\title{
Long Distance Selective Binding: The Case of Focus
}

\author{
Dag E. Wold \\ Massachusetts Institute of Technology
}

Focus belongs to a class of expressions that are insensitive to syntactic islands. Rooth (1996, 283-84) illustrates this with the sentences in (1).

(1) a. Dr. Svenson only rejected the proposal that $[\mathrm{John}]_{\mathrm{F}}$ submitted.

b. Tell me who rejected the proposal that who submitted.

In ( $1 \mathrm{~b})$, the wh-in-situ who in the relative clause must be assigned scope at the position of the first who in the Spec of CP. But raising this wh-phrase violates syntactic constraints on movement, inasmuch as the relative clause is an island for extraction:

(2) *Tell me who you rejected the proposal that t submitted.

Similarly, in (1a), the focus $\mathrm{F}$ on $J o h n_{\mathrm{F}}$ may associate with the focus sensitive operator only across a relative clause island. The link between a focus and a focus sensitive operator can be established over indefinitely long distances and can be shown to be impervious to various further island constraints.

This concern has led Rooth (1985) to develop an in situ theory of focus interpretation, in which a focused constituent such as $J o h n_{\mathrm{F}}$ in (1a) need not undergo a movement to the position of the focus sensitive operator. A variant of Kratzer's (1991) version of this in situ account is reviewed in Section 1 of this paper. This analysis makes an incorrect prediction that a focus sensitive operator unselectively binds all the foci in its scope. Section 2 devises a theory which solves this problem by treating focus sensitive operators as selective binders coindexed with the foci with which they are associated. This theory is applied to multiple focus in Section 3. Finally, Section 4 compares the expressive power of the proposed system to that of other accounts of focus interpretation.

\section{Focus Sensitive Operators as Unselective Binders}

The basic idea underlying the interpretation of focus is that a focused constituent generates a set of alternatives to that constituent. Thus, the focused NPSue evokes a set of alternatives to Sue, that is, a set of individuals. The semantic interpretation of the sentence "John introduced Sue $\mathrm{F}_{\mathrm{F}}$ to Bill" produces a set of alternative propositions which substitute an alternative individual for the focused element $\mathrm{Sue}_{\mathrm{F}}$ : 
(3) The set of alternative propositions for

"John intro Sue F $_{\mathrm{F}}$ Bill" =

$\left\{\lambda w^{\prime}\right.$ [John intro $x$ to Bill in world $\left.\left.w^{\prime}\right]: x \in D\right\}$,

where $\mathrm{D}$ is the set of individuals.

This set of alternatives is employed by a focus sensitive operator such as only which associates with the focus. As Rooth (1985) discusses, the semantics of only states that "only $\phi$ " is true only if the proposition expressed by $\phi$ is the only true proposition in the set of alternatives to $\phi$ :

(4) "only $\phi$ " is true only if given any true proposition in the set of alternatives to $\phi$, that proposition equals the proposition expressed by $\phi{ }^{\prime}$

Thus, the sentence (5), in which the focus on $\mathrm{Sue}_{\mathrm{F}}$ associates with the focus sensitive operator only, is true only if for any true proposition $\lambda w^{\prime}$ [John intro $x$ to Bill in $w^{\prime}$ ] in the set in (3), that proposition equals $\lambda w^{\prime \prime}$ [John intro Sue to Bill in $\left.w^{\prime \prime}\right]$. That is, (5) is true only if for any individual $x$ such that John introduces $\mathrm{x}$ to Bill, $\mathrm{x}=$ Sue.

(5) John only introduced $\mathrm{Sue}_{\mathrm{F}}$ to Bill.

The question arises of how to derive the set of alternatives in (3) compositionally. One method would be to move the focused constituent $S u e_{\mathrm{F}}$ to the position of the focus sensitive operator only. This movement would leave behind a trace which could straightforwardly be interpreted as a variable ranging over alternative individuals. But keeping in mind the fact that the focused phrase may be separated from the focus sensitive operator by any number of syntactic islands (cf. Anderson 1972), Rooth (1985) devises a method of producing the set of alternative propositions in (3) without syntactically moving the focused constituent. We will present here a variation on Kratzer's (1991) amendment to Rooth's theory.

Kratzer proposes that each focus feature $\mathrm{F}$ bears an index. So the logical form for (5) should be (6), where the unindexed focus $F$ is replaced by the indexed $F_{i}$.

(6) only [John intro Sue $\mathrm{Fi}_{\mathrm{i}}$ to Bill]

Indices are interpreted by assignment functions which map them into various objects. We assume that the semantic value of a logical form $\alpha$ is relativized to an assignment function $g$ : $\llbracket \alpha \rrbracket^{g}$. One of the roles of $g$ is to assign a value to the index on a pronoun. For example, using the semantic rule in (7a), the function $\mathrm{g}$ assigns the pronoun a value from the context in (7b).

(7) a. $\llbracket \mathrm{he}_{\mathrm{j}} \rrbracket^{\mathrm{g}}=\mathrm{g}(\mathrm{j})$

b. $\llbracket$ he $_{\mathrm{j}}$ intro Sue to Bill $\rrbracket^{\mathrm{g}}=$ $\lambda w[g(j)$ intro Sue to Bill in $w]$

Alongside the ordinary variable assignment g, Kratzer introduces a second 
distinguished assignment $h$ to focus variables. $h$ may be applied only to indices on foci. Relativization of the semantic value of a focused element $\alpha_{\mathrm{Fi}}$ to a focus variable assignment $h$ produces an alternative $h(i)$. If $\alpha_{\mathrm{Fi}}$ is not relativized to an alternative variable assignment, $F_{i}$ is semantically inert:

(8) Semantics of the Focus Feature $F_{i}$ :
a. $\llbracket \alpha_{\mathrm{Fi}} \rrbracket^{\text {g,h }}$ defined iff $\mathrm{i} \notin \operatorname{Dom}(\mathrm{g}) \& \mathrm{i} \in \operatorname{Dom}(\mathrm{h})$ $\llbracket \alpha_{\mathrm{Fi}} \rrbracket^{\mathrm{g}, \mathrm{h}}=\mathrm{h}(\mathrm{i})$
b. $\llbracket \alpha_{\mathrm{Fi}} \rrbracket^{\mathrm{g}}$ defined iff $\mathrm{i} \notin \operatorname{Dom}(\mathrm{g})$ $\llbracket \alpha_{\mathrm{Fi}} \rrbracket^{\mathrm{g}}=\llbracket \alpha \rrbracket^{\mathrm{g}}$

Moreover, this second assignment $\mathrm{h}$ is used only in the computation of the set of alternatives:

(9) The set of alternatives to $\phi$ is:

$\left\{\llbracket \phi \rrbracket^{\mathrm{g}, \mathrm{h}}: \mathrm{h} \in \mathrm{H}\right\}$,

where $\mathrm{H}$ is the set of focus variable assignments.

Now the informal statement of the semantics of only in (4) can be expressed as (10).

(10) $\llbracket$ only $\phi \rrbracket^{\mathrm{g}}=\lambda \mathrm{w} \forall \mathrm{p} \in\left\{\llbracket \phi \rrbracket^{\mathrm{g}, \mathrm{h}}: \mathrm{h} \in \mathrm{H}\right\}$

$$
\left[\mathrm{p}(\mathrm{w})=1 \rightarrow \mathrm{p}=\llbracket \phi \rrbracket^{\mathrm{g}}\right]
$$

Let us apply this semantic system to example (6).

(11) 【 only [John intro Sue $_{\mathrm{Fi}}$ to Bill] $\rrbracket^{\mathrm{g}}$

$=\lambda \mathrm{w} \forall \mathrm{p} \in\left\{\llbracket\right.$ John intro Sue $\mathrm{Fi}_{\mathrm{i}}$ to Bill $\left.\rrbracket^{\mathrm{g}, \mathrm{h}}: \mathrm{h} \in \mathrm{H}\right\}$

$$
\left[\mathrm{p}(\mathrm{w})=1 \rightarrow \mathrm{p}=\llbracket \text { John intro Sue } \mathrm{Fi}_{\mathrm{i}} \text { to Bill } \rrbracket^{\mathrm{g}}\right]
$$

Inside the set of alternatives, $\llbracket \mathrm{Sue}_{\mathrm{Fi}} \rrbracket^{\mathrm{g} \cdot \mathrm{h}}=\mathrm{h}(\mathrm{i})$ and outside the set of alternatives, $\llbracket$ Sue $_{\mathrm{Fi}} \rrbracket^{\mathrm{g}}=\llbracket$ Sue $\rrbracket^{\mathrm{g}}=$ Sue, by (8). Therefore, (11) can be simplified to (12).

(12) $\lambda w \forall p \in\left\{\lambda w^{\prime}\left[J\right.\right.$ intro $h(i)$ to Bill in $\left.\left.w^{\prime}\right]: h \in H\right\}$

$$
\left[\mathrm{p}(\mathrm{w})=1 \rightarrow \mathrm{p}=\lambda \mathrm{w}^{\prime \prime}\left[\mathrm{J} \text { intro Sue to Bill in } \mathrm{w}^{\prime \prime}\right]\right]
$$

$=\lambda \mathrm{w} \forall \mathrm{x}$ [John intro $\mathrm{x}$ to Bill in $\mathrm{w} \rightarrow \mathrm{x}=$ Sue $]$

This is the correct result.

Notice that in (11), the semantic value of the sister of only, 『John intro Sue $_{\mathrm{Fi}}$ to Bill \, is computed twice, once with respect to the double assignment g,h and once with respect to the single ordinary assignment g. Inside the set of

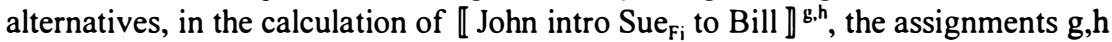
pass down to the focused constituent by virtue of the semantic composition rules, and we compute $\llbracket S_{S_{F i}} \rrbracket^{\text {b.h }}$. The focus variable assignment $h$ activates the focus feature $F_{i}$, producing an alternative $\llbracket S_{S} \rrbracket^{g, h}=h(i)$. The generation of the set of alternative propositions is thus accomplished without moving the focused phrase 
$S e_{\mathrm{Fi}}$. Outside the set of alternatives, there is no focus variable assignment $\mathrm{h}$, and so the focus feature $F_{i}$ is semantically null, yielding no alternative to the focused element: $\llbracket \operatorname{Sue}_{\mathrm{Fi}} \rrbracket^{\mathrm{g}}=\llbracket$ Sue $\rrbracket^{\mathrm{g}}=$ Sue.

This system also correctly predicts the association of more than one focus with a single focus sensitive operator. Consider example (13a) and its logical form (13b).

(13) a. John only introduced Sue $\mathrm{F}_{\mathrm{F}}$ to Bill $_{\mathrm{F}}$. (He didn't introduce Ann to Fred.)

b. only [John introduce Sue $\mathrm{Fi}_{\mathrm{Fi}}$ to $\mathrm{Bill}_{\mathrm{Fm}}$ ]

Calculation of the semantic value of (13b) gives the desired truth conditions in (14).

(14) 【only [John introduce Sue $_{\mathrm{Fi}}$ to Bill $_{\mathrm{Fm}} \rrbracket^{\mathrm{g}}$

$=\lambda \mathrm{w} \forall \mathrm{p} \in\left\{\llbracket\right.$ John introduce Sue $_{\mathrm{Fi}}$ to Bill $\left.\mathrm{Fm}_{\mathrm{Fm}} \rrbracket^{\text {g,h }}: \mathrm{h} \in \mathrm{H}\right\}$ $\left[\mathrm{p}(\mathrm{w})=1 \rightarrow \mathrm{p}=\llbracket\right.$ John introduce Sue $_{\mathrm{Fi}}$ to Bill $\left.{ }_{\mathrm{Fm}} \rrbracket^{\mathbb{g}}\right]$

$=\lambda w \forall p \in\left\{\lambda w^{\prime}\right.$ [John intro $h(i)$ to $h(m)$ in $\left.\left.w^{\prime}\right]: h \in H\right\}$ $\left[\mathrm{p}(\mathrm{w})=1 \rightarrow \mathrm{p}=\lambda \mathrm{w}^{\prime \prime}\right.$ [J intro Sue to Bill in $\left.\mathrm{w}^{\prime \prime}\right]$ ]

$=\lambda \mathrm{w} \forall \mathrm{x}, \mathrm{y}[\mathrm{J}$ intro $\mathrm{x}$ to $\mathrm{y}$ in $\mathrm{w} \rightarrow \mathrm{x}=$ Sue \& $\mathrm{y}=$ Bill $]$

The set of alternative propositions in (14) introduces a focus variable assignment $\mathrm{h}$ which percolates down to the focused elements $\mathrm{Sue}_{\mathrm{Fi}}$ and Bill $_{\mathrm{Fm}}$ and generates alternatives $h(i)$ and $h(m)$ for both of them.

In fact, in situ theories of the type found in Rooth (1985) and Kratzer (1991) predict that each focus is bound by the lowest focus sensitive operator that ccommands it. That is, in these theories, a focus sensitive operator is an unselective binder of the foci in its scope.

(15) Prediction: Each focus is absorbed by the lowest focus sensitive operator that c-commands it.

However, this prediction is falsified by cases of multiple focus discussed by Jacobs (1983), Krifka (1991), and Rooth (1994).

Consider the multiple focus example (16b) uttered in the context (16a).

(16) a. John only introduced $\mathrm{Sue}_{\mathrm{F}}$ to Fred.

(He didn't introduce anyone else to Fred.)

b. John also only introduced Sue F $_{\mathrm{F}}$ to Bill F $_{\mathrm{F}}$.

(He didn't introduce anyone else to Bill.)

In (16b), the focus on $\mathrm{Sue}_{\mathrm{F}}$ associates with only and the focus on Bill $l_{\mathrm{F}}$ is supposed to associate with the higher focus sensitive operator also. But because only is the lowest focus sensitive operator that c-commands $B_{i l l},(15)$ incorrectly predicts that only absorbs the focus on Bill $l_{\mathrm{F}}$ and consequently that no focus associates with also. 
Thus, the in situ theories of Rooth (1985) and Kratzer (1991) do not account for constructions in which one focus sensitive operator binds a focus across another focus sensitive operator. Rooth (1994) notes that a movement analysis could capture (16b) by raising Bill $_{\mathrm{F}}$ outside the scope of only, but observes that this movement violates island constraints. For example, in the multiple focus construction (17b), the focus on $J o h n_{\mathrm{F}}$ is supposed to associate with the higher focus sensitive operator also, but by (15), it will be absorbed by the lowest operator only if $J o h n_{\mathrm{F}}$ remains in situ. But if $J o h n_{\mathrm{F}}$ undergoes movement in order to escape from the scope of only, then it will have to raise out of a relative clause island, as seen in (18).

(17) a. Dr. Svenson only told $\mathrm{Sue}_{\mathrm{F}}$ about the proposal that Bill submitted.

b. Dr. Svenson also only told $\mathrm{Sue}_{\mathrm{F}}$ about the proposal that $\mathrm{John}_{\mathrm{F}}$ submitted. also $\left[\mathrm{John}_{\mathrm{F}} \lambda 2\right.$ [only [Dr. S. told $\mathrm{Sue}_{\mathrm{F}}$ about the proposal that $t_{2}$ submitted]]]

To summarize, the systems of Rooth (1985) and Kratzer (1991) for interpreting focused constituents in situ make the undesirable prediction that each focus is unselectively bound by the lowest focus sensitive operator that takes scope over it. The next section develops an analysis of focus which avoids this prediction.

\section{Focus Interpretation as Selective Variable Binding}

Let us return to the comparison between (1a) and (1b), repeated here in (19).

(19) a. Dr. Svenson only rejected the proposal that [John $]_{\mathrm{F}}$ submitted.

b. Tell me who rejected the proposal that who submitted.

In (19b), movement of the lower wh-phrase to its scope-taking position should be impeded by the relative clause island. An alternative analysis has been developed in Baker (1970), Pesetsky (1987), and Reinhart (1992). The wh-phrase remains in situ and is coindexed with an interrogative $\mathrm{Q}$ operator in Comp that specifies its scope:

(20) Tell me $Q_{\cdot j, i,}, w_{h o}\left[t_{j}\right.$ rejected the proposal that who $_{i}$ submitted]

Similarly, consider the analogy between (21a), the multiple focus example from (16b), and (2lb), a multiple wh construction.

(21) a. John also only introduced $\mathrm{Sue}_{\mathrm{F}}$ to $\mathrm{Bill}_{\mathrm{F}}$.

b. Which teacher wonders which student read which book?

In (21a), the focus on Bill $l_{\mathrm{F}}$ associates with the highest focus sensitive operator also across a lower operator only. Likewise, $(21 \mathrm{~b})$ has a reading where which book associates with the highest $\mathrm{Q}$ operator across a lower $\mathrm{Q}$ operator (producing 
answers such as "Prof. Jones wonders which student read War \& Peace). In the Baker/Pesetsky/Reinhart approach, this interpretation is represented by the structure in (22).

$\mathrm{Q}_{\mathrm{j}, \mathrm{m}>}$ which $\mathrm{w}_{\mathrm{j}}$ teacher $\mathrm{t}$ wonders $\left[\mathrm{Q}_{\mathrm{i}}\right.$ which $_{\mathrm{i}}$ student $\mathrm{t}$ read which $_{\mathrm{m}}$ book $]$

Notice that the interrogative $\mathrm{Q}$ operator does not unselectively bind all the wh in its scope. Which book associates with the highest $\mathrm{Q}$ selectively via coindexation.

Suppose we represent the connection between a focus sensitive operator and the focus that it associates with by the same mechanism, namely, coindexation. Then (19a) and (21a) will be assigned the logical forms in (23) and (24).

(23) only $\mathrm{y}_{\mathrm{i}}\left[\mathrm{Dr}\right.$. Svenson rejected the proposal that $\mathrm{John}_{\mathrm{Fi}}$ submitted]

(24) also $_{\mathrm{m}}$ [only $\mathrm{y}_{\mathrm{i}}\left[\mathrm{John}\right.$ introduce Sue $_{\mathrm{Fi}}$ to Bill $\left.\left.\mathrm{Fm}_{\mathrm{m}}\right]\right]$

Now we need a semantics for the indexed focus sensitive operators. The definition of the set of alternatives in the old system with unindexed focus sensitive operators employed relativization of the semantic value to a distinguished focus variable assignment $h$ in addition to the ordinary assignment function $g$. Let us now abolish this second assignment function $h$ and define the set of alternatives by using only the ordinary assignment $\mathrm{g}$.

(25) Old definition:

The set of alternatives corresponding to $\llbracket \mathrm{Op} \phi \rrbracket^{\mathfrak{g}}$, where $O p$ is an (unindexed) focus sensitive operator such as only, also is $\left\{\llbracket \phi \rrbracket^{\text {g.h. }} \mathrm{h} \in \mathrm{H}\right\}$.

(26) New definition: ${ }^{2}$

The set of alternatives corresponding to $\llbracket O \mathrm{p}_{\mathrm{i}} \phi \rrbracket^{\mathbb{g}}$, where $O p_{\mathrm{i}}$ is an (indexed) focus sensitive operator such as onl $y_{\mathfrak{i}}, a l s o_{i}$ is $\left\{\llbracket \phi \rrbracket^{g \cup\langle<i, x>1}: x \in D\right\}$, where $D$ is the set of individuals.

More specifically, the new entry for the indexed focus sensitive operator only will read:

(27) $\llbracket$ only $y_{i} \phi \rrbracket^{\text {g }}$ defined only if $\mathrm{i} \notin \operatorname{Dom}(\mathrm{g})$

$\llbracket$ only $_{\mathrm{i}} \phi \rrbracket^{\mathrm{g}}=\lambda \mathrm{w} \forall \mathrm{p} \in\left\{\llbracket \phi \rrbracket^{\mathfrak{g} \cup\langle\langle\mathrm{i}, \mathrm{x}\rangle\}}: \mathrm{x} \in \mathrm{D}\right\}$

$$
\left[\mathrm{p}(\mathrm{w})=1 \rightarrow \mathrm{p}=\llbracket \phi \rrbracket^{\mathrm{g}}\right]
$$

The condition $\mathrm{i} \notin \operatorname{Dom}(\mathrm{g})$ in (27) can be thought of as an instantiation of Heim's (1982) general condition that operators quantify over novel indices. This clause will ensure that foci do not act as pronouns, picking out a contextually determined referent. Rather, foci are interpreted through variable binding by an indexed focus sensitive operator.

$\phi$ in (27) will contain a focus feature $F_{i}$ coindexed with the variable binder onl $y_{\mathrm{i}}$. Since we no longer have a distinguished focus variable assignment $\mathrm{h}$, we need to redefine the semantic value of a constituent focused by $F_{i}$. Observe that 
the semantic value $\llbracket \phi \rrbracket$ is calculated with respect to the assignments $\mathrm{g}$ and $\mathrm{g} \cup\{<\mathrm{i}, \mathrm{x}>\}$ in (27).

Outside the set of alternatives, we compute $\llbracket \phi \rrbracket^{\mathrm{g}}$. $\phi$ dominates the focused constituent $\alpha_{\mathrm{Fi}}$, so that the assignment $\mathrm{g}$ percolates down by the composition rules to the calculation of $\llbracket \alpha_{\mathrm{Fi}} \rrbracket^{\mathrm{g}}$. Since this takes place outside the set of alternatives, we do not want $\llbracket \alpha_{\mathrm{Fi}} \rrbracket^{\mathrm{g}}$ to produce an alternative to $\alpha$. That is, we want $\llbracket \alpha_{\mathrm{Fi}} \rrbracket^{\mathrm{g}}=\llbracket \alpha \rrbracket^{\mathrm{g}}$.

Inside the set of alternatives in (27), we calculate $\llbracket \phi \rrbracket^{g} \cup\langle\langle i, x\rangle\}$. Once again, the composition rules pass the assignment function down to $\llbracket \alpha_{\mathrm{Fi}} \rrbracket^{g \cup\langle\langle i, x\rangle\}}$. Because this occurs inside the set of alternatives, we want $\llbracket \alpha_{\mathrm{Fi}} \rrbracket^{\mathrm{g} \cup\langle\langle i, x\rangle\}}$ to generate an alternative individual $\mathrm{x}$, which is equal to $(\mathrm{g} \cup$ $\{\langle i, x>\})(i)$. That is, we want $\llbracket \alpha_{\mathrm{Fi}} \rrbracket^{g \cup\langle<, x>\}}=(\mathrm{g} \cup\{\langle\mathrm{i}, \mathrm{x}>\})(\mathrm{i})=\mathrm{x}$.

Now observe that the difference between the assignment $g$ and $g \cup$ $\{\langle i, x\rangle\}$ is that the index $i$ is in the domain of the latter but not of the former. That $\mathrm{i} \notin \operatorname{Dom}(\mathrm{g})$ follows from (27). Combining the two desiderata that $\llbracket \alpha_{\mathrm{Fi}} \rrbracket^{\mathrm{g}}=\llbracket \alpha \rrbracket^{\mathrm{g}}$ and $\left.\llbracket \alpha_{\mathrm{Fi}} \rrbracket^{\mathrm{g} \cup} \cup\langle<\mathrm{i}, \mathrm{x}\rangle\right\}=(\mathrm{g} \cup\{<\mathrm{i}, \mathrm{x}>\})(\mathrm{i})$, we define the semantics of the focus feature $F_{i}$ in (28).

(28) New definition of the semantics of $F_{i}$ :

$$
\llbracket \alpha_{\mathrm{Fi}} \rrbracket^{\mathrm{g}}=\left\{\begin{array}{l}
\mathrm{g}(\mathrm{i}) \text { if } \mathrm{i} \in \operatorname{Dom}(\mathrm{g}) \\
\llbracket \alpha \rrbracket^{\mathrm{g}} \text { if } \mathrm{i} \notin \operatorname{Dom}(\mathrm{g})
\end{array}\right.
$$

The focus feature $F_{i}$ resembles a switch that may be turned on or of $f$ by an assignment function. An assignment $g$ whose domain contains the index $i$ of the focus feature activates the focal switch, generating an alternative $g(i)$. Otherwise, if $F_{i}$ is evaluated with respect to an assignment that cannot apply to its index, the feature remains switched off, that is, semantically inert.

Let us apply the selective binding semantics of (27) and (28) to the simple focus example (5), which now receives the logical form (29).

(29) only [John introduce Sue $_{\mathrm{Fi}}$ to Bill]

Application of (27) yields (30).

(30) $\llbracket$ only $_{\mathrm{i}}\left[\mathrm{John}\right.$ introduce $\mathrm{Sue}_{\mathrm{Fi}}$ to Bill] $\rrbracket^{\mathrm{g}}$

defined only if $\mathrm{i} \notin \operatorname{Dom}(\mathrm{g})$

$=\lambda \mathrm{w} \forall \mathrm{p} \in\left\{\llbracket\right.$ John intro Sue $\mathrm{Fi}_{\mathrm{i}}$ to Bill $\left.\rrbracket^{\mathrm{g} \cup\langle\mathrm{i}, \mathrm{x}>\}}: \mathrm{x} \in \mathrm{D}\right\}$

$\left[\mathrm{p}(\mathrm{w})=1 \rightarrow \mathrm{p}=\llbracket\right.$ John intro Sue $\mathrm{F}_{\mathrm{F}}$ to Bill $\left.\rrbracket^{\mathrm{g}}\right]$

$\mathrm{i} \in \operatorname{Dom}(\mathrm{g} \cup\{<\mathrm{i}, \mathrm{x}>\})$ and $\mathrm{i} \notin \operatorname{Dom}(\mathrm{g})$. Therefore, (28) produces $\llbracket \operatorname{Sue}_{\mathrm{Fi}} \rrbracket^{\mathrm{g} \cup} \cup\{\mathrm{i}, \mathrm{x}>\}=(\mathrm{g} \cup\{<\mathrm{i}, \mathrm{x}>\})(\mathrm{i})=\mathrm{x}$ and $\llbracket \mathrm{Sue}_{\mathrm{Fi}} \rrbracket^{\mathrm{g}}=\llbracket$ Sue $\rrbracket^{\mathrm{g}}=$ Sue. (30) then reduces to $(31)$.

(31) $\lambda w \forall p \in\left\{\lambda w^{\prime}\right.$ [John intro $x$ to Bill in $\left.\left.w^{\prime}\right]: x \in D\right\}$ $\left[\mathrm{p}(\mathrm{w})=1 \rightarrow \mathrm{p}=\lambda \mathrm{w}^{\prime \prime}\left[\mathrm{J}\right.\right.$ intro Sue to Bill in $\left.\left.\mathrm{w}^{\prime \prime}\right]\right]$ $=\lambda w \forall x[$ John intro $x$ to Bill in $w \rightarrow x=$ Sue $]$ 
So far, this system makes the same predictions for simple focus as the unselective binding semantics in Section 1 (compare (30) and (31) with (11) and (12)). In general, in our new system, if $O \mathrm{p}_{\mathrm{i}}$ is a focus sensitive operator such as onl $y_{\mathrm{i}}, a l s o_{\mathrm{i}}$, even ${ }_{\mathrm{i}}$, etc., then in the calculation of $\llbracket \mathrm{Op}_{\mathrm{i}} \phi \rrbracket^{\mathrm{g}}$, the semantic value of $\phi$ is computed with respect to $g$ outside the set of alternatives and with respect to $g \cup\{\langle i, x\rangle\}$ inside that set. By the composition rules and the semantics of $F_{i}, F_{i}$ remains semantically vacuous outside the set of alternatives since $\mathrm{i} \notin \operatorname{Dom}(\mathrm{g})$. But inside the set, the assignment $\mathrm{g} \cup\{<\mathrm{i}, \mathrm{x}\rangle\}$ is introduced, activating $F_{i}$ and producing an alternative $x$ to the focused constituent.

Now suppose that $\phi$ dominates not only $F_{i}$ but also an additional focus feature $\mathrm{F}_{\mathrm{m}}$. The assignments $\mathrm{g}$ and $\left.\mathrm{g} \cup\{<\mathrm{i}, \mathrm{x}\rangle\right\}$ will switch $\mathrm{F}_{\mathrm{m}}$ on only if the domain of $\mathrm{g}$ contains $\mathrm{m}$. This differs from the prediction of the system in Section 1. In that account, the unindexed focus sensitive operator only introduces an assignment $h$ in the set of only-alternatives that unselectively activates both features $F_{i}$ and $F_{m}$. In the new system, the indexed focus sensitive operator only selectively activates the feature $F_{i}$ while leaving the other feature $F_{m}$ in its scope intact. This is the key to solving the puzzle of multiple focus in situ, as the next section will demonstrate.

\section{Multiple Focus}

\subsection{Overlapping Focal Dependencies}

Return now to the overlapping focal dependencies in (24), repeated as (32), where also $\mathrm{m}_{\mathrm{m}}$ binds $\mathrm{F}_{\mathrm{m}}$ across an intervening operator only $\mathrm{y}_{\mathrm{i}}$.

(32) also $_{\mathrm{m}}\left[\right.$ only $\mathrm{y}_{\mathrm{i}}\left[\mathrm{John}\right.$ introduce Sue $_{\mathrm{Fi}}$ to Bill $\left.\left.\mathrm{Fm}_{\mathrm{m}}\right]\right]$

First we need a definition of the semantic value of also $o_{\mathrm{m}} \cdot a l s o_{\mathrm{m}} \phi$ asserts $\phi$ and presupposes that there exists a true alternative proposition distinct from the proposition expressed by $\phi$ :

(33) $\llbracket$ also $_{m} \phi \rrbracket^{g}(w)$ defined only if $m \notin \operatorname{Dom}(\mathrm{g}) \&$ $\exists \mathrm{q} \in\left\{\llbracket \phi \rrbracket^{g} \cup\langle\mathrm{km}, \mathrm{y}>\mathrm{y}: \mathrm{y} \in \mathrm{D}\}\left[\mathrm{q}(\mathrm{w})=1 \& \mathrm{q} \neq \llbracket \phi \rrbracket^{\mathrm{g}}\right]\right.$

Where defined, $\llbracket$ also $_{\mathrm{m}} \phi \rrbracket^{\mathrm{g}}(\mathrm{w})=\llbracket \phi \rrbracket^{\mathbb{B}}(\mathrm{w})$

For $\phi=$ the scope of also $o_{m}$ in (32), we have

(34) $\llbracket$ also $_{\mathrm{m}}\left[\right.$ only $\mathrm{y}_{\mathrm{i}}\left[\mathrm{John}\right.$ introduce $\mathrm{Sue}_{\mathrm{Fi}}$ to $\left.\left.\mathrm{Bill}_{\mathrm{Fm}}\right]\right] \rrbracket^{\mathrm{g}}(\mathrm{w})$

defined only if $m \notin \operatorname{Dom}(\mathrm{g}) \&$

$\exists q \in\left\{\llbracket\right.$ only $y_{i}\left[J\right.$ intro Sue $\mathrm{Fi}_{\mathrm{Fi}}$ to $\left.\mathrm{B}_{\mathrm{Fm}} \rrbracket^{\mathrm{g} \cup\langle\langle\mathrm{m}, y\rangle|}: \mathrm{y} \in \mathrm{D}\right\}$

$\left[\mathrm{q}(\mathrm{w})=1 \& \mathrm{q} \neq \llbracket\right.$ only $_{\mathrm{i}}\left[\mathrm{J}\right.$ intro Sue $_{\mathrm{Fi}}$ to Bill $\left.\mathrm{Fm}_{\mathrm{F}} \rrbracket^{\mathrm{g}}\right]$

Where defined, $=\llbracket$ only $y_{\mathrm{i}}\left[\mathrm{J}\right.$ intro $\operatorname{Sue}_{\mathrm{Fi}}$ to $\left.\operatorname{Bill}_{\mathrm{Fm}}\right] \rrbracket^{\mathrm{B}}(\mathrm{w})$ 
The semantic value of the c-command domain of also is relativized to $\mathrm{g} \cup$ $\{<\mathrm{m}, \mathrm{y}\rangle\}$ inside the set of also $\mathrm{m}_{\mathrm{m}}$-alternatives and to $\mathrm{g}$ outside the set of also $\mathrm{m}_{\mathrm{m}}{ }^{-}$ alternatives. Inside the set of also ${ }_{\mathrm{m}}$-alternatives, the expression "John intro $\mathrm{Sue}_{\mathrm{Fi}}$

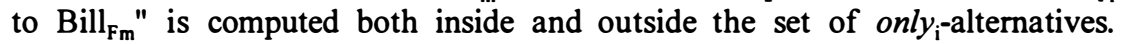
Similarly, outside the set of also ${ }_{\mathrm{m}}$-alternatives, "John intro $\mathrm{Sue}_{\mathrm{Fi}}$ to $\mathrm{Bill}_{\mathrm{Fm}}$ " is calculated inside and outside the set of only $y_{i}$-alternatives. Therefore, "John intro Sue $_{\mathrm{Fi}}$ to Bill $_{\mathrm{Fm}} "$ is computed four times in the course of expanding (34):

(35) Inside the set of also $_{\mathrm{m}}$-alternatives:

$\mathrm{m} \in \operatorname{Dom}(\mathrm{g} \cup\{<\mathrm{m}, \mathrm{y}\rangle\})$

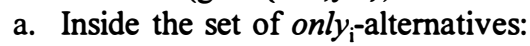

$\mathrm{i} \in \operatorname{Dom}(\mathrm{g} \cup\{<\mathrm{m}, \mathrm{y}>\} \cup\{<\mathrm{i}, \mathrm{x}>\})$

$\llbracket J$ intro $\operatorname{Sue}_{\mathrm{Fi}}$ to $\mathrm{Bill}_{\mathrm{Fm}} \rrbracket^{\mathrm{g} \cup\{\langle\mathrm{m}, \mathrm{y}\rangle\} \cup\{\langle\mathrm{i}, \mathrm{x}\rangle\}}$

$=\lambda \mathrm{w}^{\prime}$ [John intro $\mathrm{x}$ to $\mathrm{y}$ in $\mathrm{w}^{\prime}$ ]

b. Outside the set of only $y_{\mathrm{i}}$-alternatives:

$\forall \mathrm{y}$ i $\notin \operatorname{Dom}(\mathrm{g} \cup\{<\mathrm{m}, \mathrm{y}>\})$

【J intro Sue $\mathrm{Fi}_{\mathrm{Fi}}$ to $\mathrm{Bill}_{\mathrm{Fm}} \rrbracket^{\mathrm{g} \cup\{<\mathrm{m}, \mathrm{y}>\}}$

$=\lambda w^{\prime \prime}\left[\right.$ John intro Sue to $y$ in $\left.w^{\prime \prime}\right]$

(36) Outside the set of also $_{\mathrm{m}}$-alternatives:

$\mathrm{m} \notin \operatorname{Dom}(\mathrm{g})$

a. Inside the set of only $_{\mathrm{i}}$-alternatives:

$\mathrm{i} \in \operatorname{Dom}(\mathrm{g} \cup\{<\mathrm{i}, \mathrm{x}>\})$

$\llbracket \mathrm{J}$ intro $\mathrm{Sue}_{\mathrm{Fi}}$ to $\mathrm{Bill}_{\mathrm{Fm}} \rrbracket^{\mathrm{g} \cup\langle\langle\mathrm{i}, \mathrm{x}\rangle\}}$

$=\lambda w^{\prime}$ [John intro $x$ to Bill in $w^{\prime}$ ]

b. Outside the set of $o n l y_{i}$-alternatives:

$\mathrm{i} \notin \operatorname{Dom}(\mathrm{g})$

【 $\mathrm{J}$ intro Sue $_{\mathrm{Fi}}$ to Bill $_{\mathrm{Fm}} \rrbracket^{\mathrm{g}}$

$=\lambda w^{\prime \prime}[$ John intro Sue to Bill in w"]

(35) and (36) present the four basic stages in the derivation of the multiple focus construction. Applications of the semantics of the focus feature in (28) to $F_{i}$ and $F_{m}$ yield the above-results.

Notice that in (36a), only $y_{i}$ switches on only the focus feature $F_{i}$ with which it is coindexed. The other feature $F_{m}$ remains inactive since $m \notin \operatorname{Dom}(g \cup$ $\{<\mathrm{i}, \mathrm{X}\rangle\})$. This diverges from the prediction of the old account in Section 1, where only switches on every feature in its scope inside the set of only-alternatives.

To continue the derivation, (37) and (38) use the lemmas in (35) and (36) and the definition of the semantics of only in (27) to compute the semantic value of "only ${ }_{\mathrm{i}}$ [John intro Sue $\mathrm{Fi}_{\mathrm{i}}$ to Bill ${ }_{\mathrm{Fm}}$ ]." 
(37) Inside the set of also $_{\mathrm{m}}$-alternatives:

$\llbracket$ only $_{\mathrm{i}}\left[\mathrm{John}\right.$ intro Sue $\mathrm{Fi}_{\mathrm{Fi}}$ to $\left.\mathrm{Bill}_{\mathrm{Fm}}\right] \rrbracket^{\mathrm{g} \cup\langle\langle\mathrm{km}, y\rangle\}}$

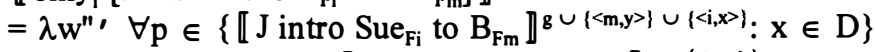
$\left[\mathrm{p}\left(\mathrm{w}^{\prime \prime}\right)^{\prime}\right)=1 \rightarrow \mathrm{p}=\llbracket \mathrm{J}$ intro $\operatorname{Sue}_{\mathrm{Fi}}$ to $\mathrm{B}_{\mathrm{Fm}} \rrbracket^{\mathrm{g} \cup\{\langle\mathrm{m}, \mathrm{y}\rangle\}]}$

$=\lambda w^{\prime \prime}, \forall p \in\left\{\lambda w^{\prime}\right.$ [John intro $x$ to $y$ in $\left.\left.w^{\prime}\right]: x \in D\right\}$

$\left[\mathrm{p}\left(\mathrm{w}^{\prime \prime \prime}\right)=1 \rightarrow \mathrm{p}=\lambda \mathrm{w}^{\prime \prime}\right.$ [J intro Sue to $\mathrm{y}$ in $\left.\left.\mathrm{w}^{\prime \prime}\right]\right]$

$=\lambda w^{\prime \prime}, \forall x$ [John intro $\mathrm{x}$ to $\mathrm{y}$ in $\mathrm{w}^{\prime \prime}, \rightarrow \mathrm{x}=$ Sue]

(38) Outside the set of also $_{\mathrm{m}}$-alternatives:

【only $\mathrm{y}_{\mathrm{i}}\left[\mathrm{John}\right.$ intro Sue $_{\mathrm{Fi}}$ to Bill $\mathrm{Fm}_{\mathrm{Fm}} \rrbracket^{\mathrm{g}}$

$=\lambda w^{\prime \prime \prime} \forall p \in\left\{\llbracket J\right.$ intro Sue $_{\mathrm{Fi}}$ to $\left.\mathrm{B}_{\mathrm{Fm}} \rrbracket^{g} \cup\langle\langle i, x\rangle\}: \mathrm{x} \in \mathrm{D}\right\}$

$\left[\mathrm{p}\left(w^{\prime \prime \prime "}\right)=1 \rightarrow \mathrm{p}=\llbracket \mathrm{J}\right.$ intro $\operatorname{Sue}_{\mathrm{Fi}}$ to Bill $\left._{\mathrm{Fm}} \rrbracket^{\mathrm{g}}\right]$

$=\lambda w^{\prime \prime \prime} \forall p \in\left\{\lambda w^{\prime}\right.$ [John intro $x$ to Bill in $w^{\prime}$ ]: $\left.x \in D\right\}$

$\left[\mathrm{p}\left(\mathrm{w}^{\prime \prime \prime}\right)=1 \rightarrow \mathrm{p}=\lambda \mathrm{w}^{\prime \prime}\left[\mathrm{J}\right.\right.$ intro Sue to $\mathrm{B}$ in $\left.\left.\mathrm{w}^{\prime \prime}\right]\right]$

$=\lambda w^{\prime \prime \prime} \forall x$ [John intro $x$ to Bill in $w^{\prime \prime \prime} \rightarrow x=$ Sue $]$

In (37), $\mathrm{y}$ is an also-alternative to Bill. (37) states that John didn't introduce anyone other than Sue to the alternative to Bill. (38) states that John didn't introduce anyone other than Sue to Bill.

After inserting the results of (37) and (38) into (34) and simplifying, we finally obtain the proper truth conditions for the multiple focus example:

(39) $\llbracket$ also $_{\mathrm{m}}\left[\right.$ only $_{\mathrm{i}}\left[\mathrm{John}\right.$ introduce $\mathrm{Sue}_{\mathrm{Fi}}$ to $\left.\left.\mathrm{Bill}_{\mathrm{Fm}}\right]\right] \rrbracket^{\mathrm{g}}(\mathrm{w})$ defined only if

$\exists y[y \neq$ Bill \& $\forall x$ [John intr $\mathrm{x}$ to $\mathrm{y}$ in $\mathrm{w} \rightarrow \mathrm{x}=$ Sue $]]$

Where defined,

$=1$ iff $\forall \mathrm{x}$ [John intro $\mathrm{x}$ to Bill in $\mathrm{w} \rightarrow \mathrm{x}=$ Sue]

\subsection{Embedded Foci}

Another kind of multiple focus example is discussed in Krifka (1991). In (40b), uttered in the context (40a), a single phrase seems to bear two distinct foci.

(40) a. John once only drank [wine $]_{F}$.

b. John also once only drank $\left[[\text { water }]_{\mathrm{F}}\right]_{\mathrm{F}}$.

Krifka suggests that water in (40b) carries two foci--the constituent water is attached to one focus feature which is embedded inside a second focused constituent. In Krifka's analyis, the inner focus associates with the higher focus sensitive operator also and the outer focus associates with the lower operator only. In our system, this means that (40b) should have a logical form like (41).

(41) also ${ }_{m}\left[\right.$ only $\left._{\mathrm{i}}\left[\text { John drink [water }{ }_{\mathrm{Fm}}\right]_{\mathrm{Fi}}\right]$ ]

Nothing new needs to be added to the semantic analysis of Section 2 in order to interpret this structure. The calculation of the semantic value of (41) proceeds in the same way as the case of multiple focus we have just discussed: 


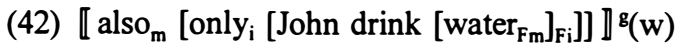

defined only if $m \notin \operatorname{Dom}(\mathrm{g}) \&$

$\exists q \in\left\{\llbracket\right.$ only $y_{\mathrm{i}}\left[\mathrm{John}\right.$ drink $\left.\left.\left[\text { water }_{\mathrm{Fm}}\right]_{\mathrm{Fi}}\right] \rrbracket^{\mathrm{g} \cup\langle<\mathrm{m}, y\rangle\}}: \mathrm{y} \in \mathrm{D}\right\}$

$\left[\mathrm{q}(\mathrm{w})=1 \& \mathrm{q} \neq \llbracket\right.$ only $\left.\left.\mathrm{y}_{\mathrm{i}}\left[\mathrm{J} \text { drink [water } \mathrm{F}_{\mathrm{Fm}}\right]_{\mathrm{Fi}}\right] \rrbracket^{\mathrm{g}}\right]$

Where defined, $=\llbracket$ only $_{\mathrm{i}}\left[\mathrm{J}\right.$ drink $\left.\left[\text { water }_{\mathrm{Fm}}\right]_{\mathrm{Fi}}\right] \rrbracket^{\mathrm{B}}(\mathrm{w})$

Once again, the computation of "John drink [ water $\left._{\mathrm{Fm}}\right]_{\mathrm{Fi}}$ " takes place four times, in conformity with the four combinations: inside/outside the set of also $_{\mathrm{m}}$ alternatives and inside/outside the set of only $y_{\mathrm{i}}$-alternatives. Accordingly, we have the lemmas in (43) and (44).

(43) Inside the set of also ${ }_{\mathrm{m}}$-alternatives: $\mathrm{m} \in \operatorname{Dom}(\mathrm{g} \cup\{<\mathrm{m}, \mathrm{y}>\})$

a. Inside the set of only $y_{\mathrm{i}}$-alternatives:

$\mathrm{i} \in \operatorname{Dom}(\mathrm{g} \cup\{<\mathrm{m}, \mathrm{y}>\} \cup\{<\mathrm{i}, \mathrm{x}>\})$

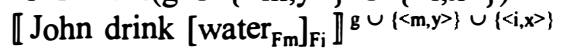

$=\lambda \mathrm{w}^{\prime}$ [John drink $\mathrm{x}$ in $\mathrm{w}^{\prime}$ ]

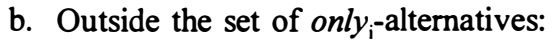

$\forall \mathrm{y}$ i $\notin \operatorname{Dom}(\mathrm{g} \cup\{<\mathrm{m}, \mathrm{y}>\})$

$\llbracket$ John drink [ water $\left._{\mathrm{Fm}}\right]_{\mathrm{Fi}} \rrbracket^{\mathcal{G} \cup\langle<\mathrm{m}, y\rangle \mid}$

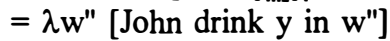

(44) Outside the set of also $_{\mathrm{m}}$-alternatives:

$\mathrm{m} \notin \operatorname{Dom}(\mathrm{g})$

a. Inside the set of only $y_{\mathrm{i}}$-alternatives:

$\mathrm{i} \in \operatorname{Dom}(\mathrm{g} \cup\{<\mathrm{i}, \mathrm{x}>\})$

$\llbracket$ John drink [ water $\left._{\mathrm{Fm}}\right]_{\mathrm{Fi}} \rrbracket \mathbb{B} \cup\{<\mathrm{i}, \mathrm{x}\rangle \mid$

$=\lambda \mathrm{w}^{\prime}$ [John drink $\mathrm{x}$ in $\mathrm{w}^{\prime}$ ]

b. Outside the set of only $y_{i}$-alternatives:

$\mathrm{i} \notin \operatorname{Dom}(\mathrm{g})$

【John drink [ water $\left._{\mathrm{Fm}}\right]_{\mathrm{Fi}} \rrbracket^{\mathrm{g}}$

$=\lambda w^{\prime \prime}[$ John drink water in w"]

The above equations follow from the semantics of the focus feature in (28). Take (43b), for example.

(45) Calculation of $\llbracket\left[\text { water }_{\mathrm{Fm}_{\mathrm{m}}}\right]_{\mathrm{F},} \rrbracket^{\mathrm{g} \cup r \cdot \mathrm{m} \cdot \mathrm{v} \cdot 1}$ in $(43 \mathrm{~b})$ :

$\llbracket\left[\text { water }_{\mathrm{Fm}_{\mathrm{m}}}\right]_{\mathrm{Fi}} \rrbracket^{\mathrm{g}} \cup+\mathrm{m} \cdot \mathrm{y}: \mathrm{F}$

$=\llbracket$ water $_{\mathrm{Fm}} \rrbracket \mathrm{g} \cup\{\cdot \mathrm{m}, \mathrm{y} \cdot$ since $\mathrm{i} \notin \operatorname{Dom}(\mathrm{g} \cup\{<\mathrm{m}, \mathrm{y}>\})$

$=(\mathrm{g} \cup\{<\mathrm{m}, \mathrm{y}>\})(\mathrm{m}) \quad$ since $\mathrm{m} \in \operatorname{Dom}(\mathrm{g} \cup\{<\mathrm{m}, \mathrm{y}>\})$

$=\mathrm{y}$ 
By the semantics of only, we have

(46) Inside the set of also $_{\mathrm{m}}$-alternatives:

$\llbracket$ only $_{i}\left[\right.$ John drink $\left.\left[\text { water }_{\mathrm{Fm}}\right]_{\mathrm{Fi}}\right] \rrbracket^{\mathrm{g} \cup\{<\mathrm{m}, \mathrm{y}>\}}$

$=\lambda w^{\prime \prime}, \forall p \in\left\{\llbracket J\right.$ drink $\left.\left[\text { water }_{\mathrm{Fm}}\right]_{\mathrm{Fi}} \rrbracket g \cup\{\langle\mathrm{m}, y\rangle\} \cup\{\langle\mathrm{i}, \mathrm{x}\rangle\}: \mathrm{x} \in \mathrm{D}\right\}$

$\left[\mathrm{p}\left(\mathrm{w}^{\prime \prime \prime}\right)=1 \rightarrow \mathrm{p}=\llbracket \mathrm{J}\right.$ drink $\left.\left[\text { water }_{\mathrm{Fm}}\right]_{\mathrm{Fi}} \rrbracket^{\mathrm{g} \cup\langle<\mathrm{m}, \mathrm{y}>\}}\right]$

$=\lambda w^{\prime \prime}, \forall p \in\left\{\lambda w^{\prime}\right.$ [John drink $x$ in $w^{\prime}$ ] $\left.x \in D\right\}$

$\left[\mathrm{p}\left(\mathrm{w}^{\prime \prime \prime}\right)=1 \rightarrow \mathrm{p}=\lambda \mathrm{w}^{\prime \prime}\left[\mathrm{J}\right.\right.$ drink $\mathrm{y}$ in $\left.\left.\mathrm{w}^{\prime \prime}\right]\right]$

$=\lambda \mathrm{w}^{\prime \prime}, \forall \mathrm{x}$ [John drink $\mathrm{x}$ in $\mathrm{w}^{\prime \prime}, \rightarrow \mathrm{x}=\mathrm{y}$ ]

(47) Outside the set of also $_{\mathrm{m}}$-alternatives:

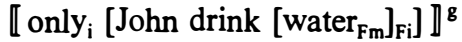

$\left.=\lambda w^{\prime \prime \prime} \forall p \in\left\{\llbracket \text { John drink [water }{ }_{F m}\right]_{F i} \rrbracket^{g \cup\langle\langle i, x\rangle\}}: x \in D\right\}$

$\left[\mathrm{p}\left(\mathrm{w}^{\prime \prime \prime \prime}\right)=1 \rightarrow \mathrm{p}=\llbracket\right.$ John drink $\left.\left[\text { water }_{\mathrm{Fm}}\right]_{\mathrm{Fi}} \rrbracket^{\mathrm{g}}\right]$

$=\lambda w^{\prime \prime \prime} \forall p \in\left\{\lambda w^{\prime}\right.$ [John drink $x$ in $\left.\left.w^{\prime}\right]: x \in D\right\}$

$\left[\mathrm{p}\left(\mathrm{w}^{\prime \prime \prime}\right)=1 \rightarrow \mathrm{p}=\lambda \mathrm{w}^{\prime \prime}\left[\right.\right.$ John drink water in $\left.\mathrm{w}^{\prime \prime}\right]$ ]

$=\lambda w^{\prime \prime " ~} \forall \mathrm{x}$ [John drink $\mathrm{x}$ in $\mathrm{w}^{\prime \prime \prime} \rightarrow \mathrm{x}=$ water $]$

(46) says that John drank nothing other than y, where y is an also-alternative to water, and (47) means that John drank nothing other than water.

Substitution of these results back into (42) and simplifying produces the desired truth conditions. ${ }^{3}$

(48) $\llbracket$ also $_{m}\left[\right.$ only $_{i}\left[\right.$ John drink $\left.\left.\left[\text { water }_{\mathrm{Fm}}\right]_{\mathrm{Fi}}\right]\right] \rrbracket^{\mathrm{g}}(\mathrm{w})$

defined only if

$\exists \mathrm{y}[\mathrm{y} \neq$ water $\& \forall \mathrm{x}$ [John drink $\mathrm{x}$ in $\mathrm{w} \rightarrow \mathrm{x}=\mathrm{y}]$ ]

Where defined,

$=1$ iff $\forall \mathrm{x}$ [John drink $\mathrm{x}$ in $\mathrm{w} \rightarrow \mathrm{x}=$ water]

The semantic system that we have devised accounts for multiple focus by permitting foci to be selectively bound by focus sensitive operators. It is therefore clearly more expressive than the unselective binding semantics of Section 1. The next section of fers a few comments about the degree of expressiveness of this new system in relation to other theories that have been proposed in the literature.

\section{Comparisons with Other Systems}

\subsection{The Focus Interpretation Operator}

Rooth (1992) introduces an operator which encodes the general properties of focus sensitive operators such as only, also, and even. In this theory, each focus feature $F$ is found in the scope of a focus interpretation operator $\sim$. In the representation (49), only no longer interprets the focus feature directly. $F$ is interpreted by the $\sim$ operator which has two arguments, $v_{j}$ and "John intro Sue $\mathrm{F}_{\mathrm{F}}$ to Bill." $v_{j}$ is anaphoric to a set of propositions and $\sim$ constrains $v_{j}$ to be a set of alternatives to "John intro Sue ${ }_{\mathrm{F}}$ to Bill." Only associates with F by sharing the 
common argument $\mathrm{v}_{\mathrm{j}}$ with $\sim$.

(49) only $\left(v_{j}\right)\left[\sim\left(v_{j}\right)\right.$ [John intro Sue ${ }_{\mathrm{F}}$ to Bilt] $]$

This framework can be integrated with the semantics that we have proposed by allowing $\sim$ to be selectively coindexed with the feature $F$ to which it is linked:

(50) only $\left(v_{j}\right)\left[\sim_{i}\left(v_{j}\right)\left[\right.\right.$ John intro Sue $e_{\mathrm{Fi}}$ to Bill] $]$

$\sim_{i}$ is interpreted roughly as in (51).

(51) $\llbracket \sim_{i}\left(v_{j}\right) \phi \rrbracket^{g}$

presupposes that $g(j)$ is the set of alternatives

$\left\{\llbracket \phi \rrbracket^{g \cup\langle<i, x\rangle \mid}: x \in D\right\}$ asserts $\llbracket \phi \rrbracket^{\mathrm{g}}$

\subsection{Structured Meanings}

In the Structured Meanings approach to focus interpretation (see, for example, Jacobs 1983, Krifka 1991, and von Stechow 1991), the scope of the focus sensitive operator only in (52) is interpreted as a pair consisting of the characteristic function of a set of alternatives to the focused constituent and the focused constituent itself.

(52) only [John introduce Sue F $_{\mathrm{F}}$ to Bill]

(53) "John intro Sue to Bill" interpreted as

$\left\langle\lambda \mathrm{x} \lambda \mathrm{w}^{\prime}\right.$ [John intro $\mathrm{x}$ to Bill in $\mathrm{w}^{\prime}$ ], Sue $>$

The operator only combines with this pair to produce "Given any $\mathrm{x}$ satisf ying the first member of the pair, $x=$ the second member of the pair.

Rooth (1996) argues that the Structured Meanings approach is too expressive. He discusses a hypothetical focus sensitive operator tolf which has the interpretation "y tolf $\phi$ " is true iff y tells $\alpha$ that $\phi$, where $\alpha$ is the meaning of the focused constituent dominated by $\phi$. For instance, (54a) would mean (54b).

(54) a. Fred tolfed that John introduced Sue $\mathrm{F}_{\mathrm{F}}$ to Bill.

b. Fred told Sue that John introduced Sue to Bill.

Operators like tolf apparently do not exist in natural language, and so a theory of focus should be restrictive enough to exclude them. However, the theory of Structured Meanings does not conform to this requirement. The embedded clause in (54a) is interpreted as the structured pair $\left\langle\lambda x \lambda w^{\prime}\right.$ [J intro $x$ to Bill in $w^{\prime}$ ], Sue $>$. Then it is unproblematic to define "tolf $<X, \alpha>$ " as "tell $\alpha$ that $X(\alpha)$." Too much information is recoverable from a structured representation. In particular, the meaning of the focused constituent can be accessed from the structured format and then used to construct an impossible verb tolf. 
Manfred Krifka (personal communication) has pointed out that the selective in situ binding semantic system of Section 2 is less expressive than Structured Meanings and more expressive than Rooth's (1985) Alternative Semantics. It is more restrictive than Structured Meanings because the meaning of the focused constituent cannot in general be obtained from the representation. Consider a clause $\phi$ that dominates a focused phrase $\alpha_{\mathrm{Fi}}$ If a focus sensitive operator $O \mathrm{p}_{\mathrm{i}}$ applies to this clause relative to an assignment $\mathrm{g}, \mathrm{Op}_{\mathrm{i}}$ can access the meanings $\llbracket \phi \rrbracket^{g}$ and $\llbracket \phi \rrbracket^{g} \cup\langle\langle i, x\rangle\}$, but cannot in general recover $\llbracket \alpha_{\mathrm{Fi}} \rrbracket^{\mathrm{g}}$.

In addition, structured representations mimic the effects of syntactic movement. In a sense, the structured format is isomorphic to a representation in which the focused constituent has raised, leaving behind a trace. On the other hand, our proposed in situ binding theory does not employ movement of the focused phrase, nor does it mirror syntactic movement in the semantic representation.

\subsection{Alternative Semantics}

The theory of interpreting foci in situ developed in Rooth (1985) is known as Alternative Semantics (von Stechow 1989). To derive the set of alternatives without moving the focused constituent, this theory introduces a distinction between two semantic values, the ordinary semantic value 【 \and the focus semantic value 【 $\rrbracket^{f}$. Focus features $\mathrm{F}$ are unindexed and are activated by the focus value $\llbracket \rrbracket^{\mathrm{f}}$, which produces a set of alternatives. $\mathrm{F}$ is semantically vacuous with respect to the ordinary value 【 $\rrbracket$.

(55) a. $\llbracket \operatorname{Sue}_{\mathrm{F}} \rrbracket^{\mathrm{f}}=\{\mathrm{x}: \mathrm{x} \in \mathrm{D}\}$

b. $\llbracket \mathrm{Sue}_{\mathrm{F}} \rrbracket=$ Sue

(56) a. 『John introduced $S e_{F}$ to Bill $\rrbracket^{f}$

$=\left\{\lambda w^{\prime}\left[\right.\right.$ John intro $x$ to Bill in $\left.\left.w^{\prime}\right]: x \in D\right\}$

b. 【John introduced Sue $_{\mathrm{F}}$ to Bill $\rrbracket$

$=\lambda w^{\prime \prime}[$ John intro Sue to Bill in w"]

The focus semantic value gives the set of alternatives that is used by the focus sensitive operators. But because the focus value of a clause activates all the foci dominated by that clause, Alternative Semantics makes the prediction in (15) that a focus is captured by the lowest c-commanding focus sensitive operator. Alternative Semantics cannot account for the binding of a focus by one operator across another intervening operator without moving the focus and is therefore less expressive than the selective in situ binding theory of Section 2 .

The question may be asked of exactly how much needs to be added to Alternative Semantics in order for it to reach the degree of expressive power of the proposed selective binding system. Consider a system that we will call Augmented Alternative Semantics, that is, Alternative Semantics augmented by selective variable binding. This system will turn the focus sensitive operators into variable binders--the operator is coindexed with a focus that it associates with, and both the ordinary and focus semantic values are relativized to an assignment function $g$ that mediates variable binding. Augmented Alternative Semantics will 
retain the distinction between the two semantic values, but instead of the focus value producing a set of alternatives, the focus value will represent the alternative itself. Thus, Augmented Alternative Semantics replaces (55) and (56) with (57) and (58).

(57) a. $\llbracket \mathrm{Sue}_{\mathrm{Fi}} \rrbracket^{\mathrm{f} g \mathrm{~g}}=\mathrm{g}(\mathrm{i})$

b. $\llbracket \mathrm{Sue}_{\mathrm{Fi}} \rrbracket^{\mathrm{g}}=\llbracket$ Sue $\rrbracket^{\mathrm{g}}=$ Sue

(58) a. 【John introduced Sue $\mathrm{Fi}_{\mathrm{Fi}}$ to Bill $\rrbracket^{\mathrm{f} ; \mathrm{g}}$

$=\lambda \mathrm{w}^{\prime}$ [John intro $\mathrm{g}(\mathrm{i})$ to Bill in $\left.\mathrm{w}^{\prime}\right]$

b. 【John introduced Sue $\mathrm{Fi}_{\mathrm{Fi}}$ to Bill \g

$=\lambda w^{\prime \prime}$ [John intro Sue to Bill in w"]

The semantics of only $\phi$ employs the focus value to generate the set of alternatives:

(59) $\llbracket$ only ${ }_{i} \phi \rrbracket^{g}$ defined only if $\mathrm{i} \notin \operatorname{Dom}(\mathrm{g})$

$=\lambda \mathrm{w} \forall \mathrm{p} \in\left\{\llbracket \phi \rrbracket^{\mathrm{f} ; \mathrm{g} \cup\langle<\mathrm{i}, \mathrm{x}\rangle\}}: \mathrm{x} \in \mathrm{D}\right\}\left[\mathrm{p}(\mathrm{w})=1 \rightarrow \mathrm{p}=\llbracket \phi \rrbracket^{\mathrm{g}}\right]$

Is Augmented Alternative Semantics equivalent to the system we devised in Section 2? $?^{4}$ The answer is that Augmented Alternative Semantics is still too restrictive. It cannot capture the behavior of multiple foci in situ. To see this, return to the calculation of the semantic value of the multiple focus example (32). Recall that 【John intro $\mathrm{Sue}_{\mathrm{Fi}}$ to $\mathrm{Bill}_{\mathrm{Fm}} \rrbracket$ was computed four times, with the results shown in (35) and (36). (35) and (36) exhibit the pattern of desired focal switch settings of the features $F_{i}$ and $F_{m}$ that derive the correct truth conditions for multiple focus. Compare this pattern with the one in (60) and (61) generated by Augmented Alternative Semantics.

(60) Inside the set of also $_{\mathrm{m}}$-alternatives:

a Inside the set of only $_{\mathrm{i}}$-alternatives:

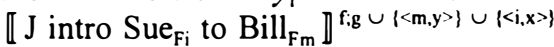

$=\lambda \mathrm{w}^{\prime}$ [John intro $\mathrm{x}$ to $\mathrm{y}$ in $\mathrm{w}^{\prime}$ ]

b. Outside the set of only $y_{\mathrm{i}}$-alternatives:

$\llbracket \mathrm{J}$ intro Sue $_{\mathrm{Fi}}$ to $\mathrm{Bill}_{\mathrm{Fm}} \rrbracket^{\mathrm{g} \cup\{<\mathrm{m}, \mathrm{y}>\}}$

$=\lambda w^{\prime \prime}$ [John intro Sue to Bill in w"]

(61) Outside the set of also $_{\mathrm{m}}$-alternatives:

a. Inside the set of only $y_{i}$-alternatives:

$\llbracket \mathrm{J}$ intro Sue $_{\mathrm{Fi}}$ to Bill $\mathrm{Fm}_{\mathrm{F}} \rrbracket_{\mathrm{f}, \mathrm{g} \cup\{-\mathrm{i}, \mathrm{x}>\boldsymbol{1}}$

$=\lambda \mathrm{w}^{\prime} \quad\left[\mathrm{J}\right.$ intro $\mathrm{x}$ to $(\mathrm{g} \cup\{<\mathrm{i}, \mathrm{x}>\})(\mathrm{m})$ in $\left.\mathrm{w}^{\prime}\right]$

b. Outside the set of only $y_{\mathrm{i}}$-alternatives:

$\llbracket \mathrm{J}$ intro $\mathrm{Sue}_{\mathrm{Fi}}$ to $\mathrm{Bill}_{\mathrm{Fm}} \rrbracket^{\mathrm{g}}$

$=\lambda w^{\prime \prime}$ [John intro Sue to Bill in w"]

There are two discrepancies between $(35) /(36)$ and $(60) /(61)$. Inside the set of also-alternatives and outside the set of only-alternatives, (35b) generates an alternative to Bill $_{\mathrm{Fm}}$, but $(60 \mathrm{~b})$ does not. In fact, Rooth $(1994, \S 7)$ 
tried to devise a version of Augmented Alternative Semantics, but observing the problem posed by $(60 \mathrm{~b})$, he abandoned this attempt. Similarly, outside the set of also-alternatives and inside the set of onlyalternatives, (36a) produces no also-alternative to Bill $_{\mathrm{Fm}}$, but (61a) does. In (61a), $(g \cup\{<i, x>\})(m)$ is not even defined. Even if we make the assignments total functions, this will not prevent (61a) from wrongly assigning an also-alternative to Bill $_{\mathrm{Fm}}$.

Thus, simply enriching Alternative Semantics by a variable binding mechanism is not enough to derive multiple focus. The source of the inaccurate predictions in (60b) and (61a) is the definition of the semantics of the focus feature in (57). The focus value 【 $\rrbracket^{\mathrm{fig}}$ always activates the focus feature, whereas the ordinary value 【 $\rrbracket^{\mathrm{g}}$ never does. Augmented Alternative Semantics cannot handle "mixed" cases, where one focus feature is switched on and another is switched off simultaneously. The semantics of the focus feature is too rigid.

In order to ensure that $\llbracket \mathrm{Bill}_{\mathrm{Fm}} \rrbracket$ produces a

$\mathrm{n}$ alternative but $\llbracket \mathrm{Sue}_{\mathrm{Fi}} \rrbracket$ does not in $(60 \mathrm{~b})$, we need to change the definition of the ordinary semantic value of the focus feature to (62).

$$
\llbracket \alpha_{F i} \rrbracket^{g}=\left\{\begin{array}{c}
g(i) \text { if } i \in \operatorname{Dom}(g) \\
\llbracket \alpha \rrbracket^{g} \text { if } i \notin \operatorname{Dom}(g)
\end{array}\right.
$$

Similarly, altering the definition of the focus semantic value to (63) will ensure that $F_{m}$ remains semanically null but $F i$ is activated in (61a).

$$
\llbracket \alpha_{F i} \rrbracket^{f ; g}=\left\{\begin{array}{l}
g(i) \text { if } i \in \operatorname{Dom}(g) \\
\llbracket \alpha \rrbracket^{f ; g} \text { if } i \notin \operatorname{Dom}(g)
\end{array}\right.
$$

But now notice that the ordinary and focus values of an expression are always identical. The modification that we made to Alternative Semantics in order to correctly capture the semantics of multiple focus constructions turns out to be exactly the change needed to eliminate the distinction between the ordinary and focus semantic values. Augmented Alternative Semantics together with the alterations in (62) and (63) becomes the semantic system in Section 2.

To summarize, for Alternative Semantics to reach the degree of expressiveness of our proposed in situ selective binding theory, it needs to incorporate not only selective variable binding, but also a more flexible semantics of the focus feature which collapses the ordinary/focus semantic value distinction.

This paper has elaborated an approach to the semantics of focus which is intermediate in expressive power between Alternative Semantics and Structured Meanings. Foci are interpreted through a selective variable binding mechanism which can establish a link between a focus and the operator that binds it over long distances--across islands and intervening operators--without moving the focused element. The focus feature behaves like a switch that remains semantically inert until activated by an assignment function introduced by the focus sensitive operator. 


\section{Endnotes}

* Versions of this paper have been presented at the Workshop on Focus at the University of Massachusetts, Amherst, the Winter Workshop of the Israeli Association for Theoretical Linguistics at the Technion in Haifa, and SALT VI. I would like to thank the participants in these conferences, and also Kai von Fintel, Jim Harris, Irene Heim, Manfred Krifka, Alec Marantz, David Pesetsky, Amim von Stechow, and the participants in the spring 1994 generals workshop at MIT for their valuable comments and assistance.

1. This paper ignores the presupposition of "only $\phi$ " that $\phi$ is true.

2. This definition makes the simplifying assumption that only elements of individual type may be focused. It can be easily generalized.

3. Technically these truth conditions are inconsistent since we have suppressed the semantics of once in (40b) in order to simplify the calculation.

4. Amim von Stechow (personal communication) has also posed this question for a similar system of Augmented Alternative Semantics.

\section{References}

Anderson, S. 1972. "How to Get even." Language 48, 893-906.

Baker, C.L. 1970. "Notes on the Description of English Questions: The Role of an Abstract Question Morpheme." Foundations of Language 6, 197-219.

Heim, I. 1982. The Semantics of Definite and Indefinite Noun Phrases. Ph.D. dissertation, University of Massachusetts, Amherst.

Jacobs, J. 1983. Fokus und Skalen: Zur Syntax und Semantik von Gradpartikeln im Deutschen, Tübingen: Niemeyer.

Kratzer, A. 1991. "The Representation of Focus." In Semantics: An International Handbook of Contemporary Research, eds. A. von Stechow \& D. Wunderlich. Berlin: Walter de Gruyter, 825-834.

Krifka, M. 1991. "A Compositional Semantics for Multiple Focus Constructions." In Proceedings of the First Semantics and Linguistic Theory Conference: SALT I, eds. S. Moore \& A.Z. Wyner. Published under Cornell Working Papers in Linguistics, Number 10, 127-158.

Pesetsky, D. 1987. "Wh-in-Situ: Movement and Unselective Binding." In The Representation of (In)definiteness, eds. E.J. Reuland \& A.G.B. ter Meulen. Cambridge, MA: The MIT Press, 98-129.

Reinhart, T. 1992. "Interpreting Wh-in-Situ." ms.

Rooth, M. 1985. Association with Focus. Ph.D. dissertation, University of Massachusetts, Amherst.

Rooth, M. 1992. "A Theory of Focus Interpretation." Natural Language Semantics $1,75-116$.

Rooth, M. 1994. "A Hybrid Architecture for Focus." Talk presented at MIT, February 17.

Rooth, M. 1996. "Focus." In The Handbook of Contemporary Semantic Theory, ed. S. Lappin. Cambridge, MA: Blackwell, 271-297. 
von Stechow, A. 1989. Focusing and Backgrounding Operators, Technical Report 6, Fachgruppe Sprachwissenschaft, Universität Konstanz.

von Stechow, A. 1991. "Current Issues in the Theory of Focus." In Semantics: An International Handbook of Contemporary Research, eds. A. von Stechow \& D. Wunderlich. Berlin: Walter de Gruyter, 804-825. 